\title{
La naturaleza de las entidades matemáticas. Gassendi y Mersenne: objetores de Descartes
}

\section{[The Nature of Mathematical Entities. Descartes and His Detractors: Gassendi and Mersenne]}

\author{
Soledad AlEJANDra VelázQuez ZaragozA \\ Escuela Nacional Preparatoria \\ Facultad de Filosofía y Letras \\ Facultad de Estudios Superiores Acatlán \\ Universidad Nacional Autónoma de México \\ s.alejandravelazquez@gmail.com
}

\begin{abstract}
Resumen: La naturaleza de las entidades matemáticas ha sido un problema filosófico recurrente en diversas épocas; aquí mostraré que fue una pieza clave en la definición de las posturas ontológicas durante la Modernidad temprana. La piedra de toque para la fundamentación de los conocimientos científicos fue el carácter que se atribuyó a las entidades matemáticas - -y, en general, a las entidades abstractas, incluidas las lógicas - en la filosofía natural. Expongo dos posiciones de la Modernidad: la que defendió René Descartes, quien las concibió como entidades perennes, inherentes a la propia constitución y funcionamiento de la mente y la de autores como Pierre Gassendi y Marin Mersenne, quienes defendieron el origen empírico e instrumental de esas entidades.
\end{abstract}

Palabras clave: verdades eternas, instrumentalismo, entidades abstractas, matemáticas, críticos de Descartes

\begin{abstract}
The status of mathematical entities has been a recurrent philosophical problem in different times; here I explain how it was a key piece in the definition of ontological positions during Early Modernity. The touchstone for the foundation of scientific knowledge was the character assigned to mathematical entities - and, in general, to abstract entities, including logical ones- within the natural philosophy. I sketch two modern positions: on the one hand, the one defended by René Descartes, who assigned mathematical items a status of perennial entities, inherent to the very constitution and operation of the mind and, on the other, the one supported by authors such as Pierre Gassendi and Marin Mersenne, who defended the empirical and instrumental origin of those entities.
\end{abstract}

Key words: eternal truths, instrumentalism, abstract entities, mathematics, polemicist of Descartes

\section{Introducción}

La reflexión sobre el carácter ontológico de las entidades matemáticas aparece en la agenda filosófica en diversos periodos históricos. Las polémicas que ha suscitado ilustran el carácter vigente de las discusiones 
clásicas y cómo éstas trazan rutas permanentes, a pesar de sus cambios de ropaje discursivo por las coyunturas y contextos específicos. Así, la defensa del carácter irreductible de las entidades matemáticas a procesos empíricos o la postura de que estas entidades pueden reducirse a procesos que se originan en nuestra experiencia pueden encontrarse en distintas versiones en diferentes épocas. En este estudio abordaré esta discusión en el escenario de la Modernidad temprana a través del debate —expuesto en las Meditaciones metafísicas (1641) - ${ }^{1}$ entre René Descartes (1596-1650) y dos de sus interlocutores: Pierre Gassendi (1592-1655) y Marin Mersenne (1588-1848).

En esta introducción me interesa resaltar la perdurabilidad de la polémica, por lo que, a manera de ejemplo, ofreceré un vistazo a los inicios del siglo XX, donde podemos encontrar en Gottlob Frege (18481925) a uno de los defensores más puntuales de la postura irreductibilista por sostener que la naturaleza de las entidades aritméticas constituye un "tercer reino". A este territorio corresponden las verdades intemporales, incorregibles, aun cuando no haya alguien que las reconozca como tales. Este tercer reino debe distinguirse tanto del ámbito de las cosas como de sus representaciones. Como señala el propio Frege:

[L]os pensamientos no son ni objetos del mundo exterior ni representaciones. Hay que reconocer un tercer dominio. Lo que pertenece a ese dominio tiene en común con las representaciones que no puede ser percibido por los sentidos, y con los objetos, que no necesita de un portador a cuyos contenidos de conciencia pertenezca. Así, por ejemplo, el pensamiento que expresamos en el teorema de Pitágoras es atemporalmente verdadero, es verdadero independientemente de si alguien lo considera verdadero. No necesita de un portador. Es verdadero no sólo a partir de que fue descubierto; así como un planeta, aun antes de que alguien lo haya visto, ya ha estado interactuando con otros planetas. (Frege 1996, pp. 37-38)

Así, de acuerdo con Frege, la naturaleza de las proposiciones aritméticas no es en modo alguno reducible a sus aplicaciones físicas. ${ }^{2}$ Supo-

${ }^{1}$ Como se sabe, la singularidad de las Meditaciones metafísicas radica en la inclusión de las objeciones de diversos interlocutores de Descartes —seis series—, así como las respuestas de éste. Por ello, las Meditaciones son un espacio privilegiado en la historia del pensamiento moderno para seguir el debate sobre varios temas filosóficos, centrales para la fundamentación de la nueva ciencia.

${ }^{2}$ Para profundizar en este tema conviene revisar la biografía intelectual de Frege escrita por Richard L. Mendelsohn y donde se lee lo siguiente: "Su polémica contra 
ner la posibilidad de tal reducción es incurrir en cierta confusión; por ejemplo, la del psicologismo de John Stuart Mill (1806-1873) quien, en opinión del filósofo alemán, "confunde siempre las aplicaciones que pueden hacerse de una proposición aritmética, las cuales son frecuentemente de índole física y tienen como presupuesto situaciones fácticas observadas, con las proposiciones matemáticas puras mismas" (Frege 1972 , p. 124). Por ejemplo, Mill considera que la igualdad $1=1$ no es necesariamente verdadera, ya que, por ejemplo, una libra de peso nunca pesa lo mismo que otra. Sin embargo, Frege añade:

[L]a proposición $1=1$ en manera alguna pretende afirmar esto. Mill entiende el símbolo + de tal manera que por medio de él se expresen las relaciones de las partes de [...] un cuerpo físico pero éste no es el sentido de este símbolo. $5+2=7$ no significa que si en 5 partes de líquido se vierten 2 partes de líquido se obtendrá 7 partes de líquido, sino que ésta es una aplicación de aquella proposición. (Frege 1972, p. 124)

En efecto, para Mill los axiomas y definiciones de la aritmética son resultado de la inducción, sus verdades fundamentales se derivan del testimonio de los sentidos, por lo que son meras generalizaciones que se originan en la experiencia. De este modo, ante las preguntas “¿cuál es el fundamento de nuestra creencia en los axiomas?" y “ien dónde reposa su evidencia?", Mill responde: "Son verdades experimentales, generalidades de la observación. La proposición: dos líneas rectas no pueden encerrar un espacio o, en otros términos, dos líneas rectas que se han encontrado una vez no se encuentran más y continúan divergiendo, es una inducción resultante del testimonio de los sentidos" (Mill 1917, p. 252). ${ }^{3}$ Según el filósofo inglés, ésta es la misma condición de la ciencia de los números:

¿Cómo saber que una libra y una libra hacen dos libras, si una de ellas es de doce onzas y la otra de diez y seis? ¿Cómo podemos saber que una fuerza de 40 caballos es siempre igual, a menos de suponer que todos los caballos son de igual fuerza? Es cierto que 1 es siempre igual en número a 1 , y siempre que no se trate absolutamente más que del número de los

las posturas de sus contemporáneos empiristas y naturalistas en torno al concepto de número es devastadora. Frege consideró erróneas esas concepciones no sólo en sus aspectos específicos, sino también en su metodología para la búsqueda de la fundamentación de las matemáticas" (Mendelsohn 2005, p. 3; la traducción es mía).

${ }^{3}$ Libro II, cap. V, "De la demostración y de las verdades necesarias", \#4. 
objetos o de las partes de un objeto, sin suponer que son equivalentes bajo otro aspecto, las conclusiones aritméticas limitadas a esto solamente, son verdaderas, sin mezcla de hipótesis. Hay algunos casos raros de este género. (Mill 1917, p. 281)

Por lo anterior, la certidumbre de la aritmética (i.e., la identidad del número) rara vez se da y sólo bajo condiciones muy acotadas; mientras que la que se atribuye a la geometría, en la mayoría de los casos, es semejante a la certidumbre hipotética pues se asienta en generalidades observadas.

Esta breve muestra de la distancia del irreductibilismo de Frege en relación con el psicologismo de Mill basta aquí para hacer patente la permanencia de la polémica que me ocupa en este escrito. La discusión que sostuvieron René Descartes y los también filósofos galos Pierre Gassendi y Marin Mersenne evidencia la controversia en torno al estatus ontológico de las entidades abstractas (matemáticas y lógicas) que tuvo lugar en el contexto de la fundamentación de la nueva ciencia durante el siglo XVII. Defensor de la postura irreductibilista, Descartes encuentra en Gassendi y Mersenne a dos detractores con estilos contrastantes: el primero de ellos, como lo veremos, rotundo y desafiante; el segundo, en cambio, discreto y mesurado, pero ambos rivales dispuestos a enfrentarlo en el espacio de las Objeciones y respuestas que el mismo Descartes previó en las Meditaciones metafísicas para enfrentarse a los intelectuales de su tiempo.

La peculiaridad de esta disputa está no sólo en que sus protagonistas tuvieron la oportunidad de conocer las posturas de sus rivales a fondo - considérese, por ejemplo, la cercanía de Mersenne con Descartes, de quien fuera, como es bien sabido, su más frecuente corresponsal-. Asimismo, Descartes y Gassendi pudieron confrontar sus visiones de manera directa como interlocutores en las quintas objeciones y sus respuestas, con lo que legaron uno de los episodios más notables de la historia de la reflexión filosófica en que se plantea la naturaleza ontológica de las entidades abstractas.

La discusión entre Descartes y Gassendi aborda diferentes temas que han sido objeto de importantes análisis. ${ }^{5}$ Sin embargo y a pesar de su

${ }^{4}$ Libro II, cap. VI, "Continuación del mismo asunto", \#3.

${ }^{5}$ Entre ellos, destaca el estudio de Thomas M. Lennon, quien afirma que el debate entre los partidarios de Descartes y de Gassendi fue el más importante de la segunda mitad del siglo XVII para reemplazar en materia científica al aristotelismo al enfrentarse al escepticismo y erigir la Nueva Ciencia (cfr. Lennon 1993). Asimismo, Martha Bolton aborda de manera esclarecedora el tema de las teorías de los 
riqueza, el problema del estatus ontológico de las entidades lógicas y matemáticas ha sido aún poco estudiado, lo cual parece ser consecuencia de una lectura parcial de las Meditaciones metafísicas debido a que algunas de sus ediciones prescinden a menudo de las objeciones y respuestas. Menos conocida aún es la postura de Marin Mersenne, pues, a pesar de haber sido un matemático importante en su tiempo y de haber reflexionado en términos filosóficos sobre este aspecto en particular, sus escritos son casi desconocidos en la actualidad, pues no se dispone de ediciones modernas de la mayor parte de ellos. La postura de Mersenne se advierte en las series segunda y sexta de objeciones dirigidas a Descartes; empero, en este contexto la voz del padre mínimo no se ha articulado a las concepciones que expresa en el resto de sus obras.

En vista del panorama anterior, me propongo aquí contribuir al estudio de la naturaleza ontológica de las entidades lógicas y matemáticas, problema de profundo interés en el ambiente intelectual de aquella época - aunque, como lo hemos visto, no exclusivo de ella- y, asimismo, relevante para la fundamentación conceptual de la nueva ciencia. En la primera parte, revisaré los principales argumentos de la discusión entre Descartes y Gassendi y, en la segunda, examinaré los que se esgrimieron entre el filósofo de la Touraine y Mersenne. Mi análisis de estos últimos se suma, en esta ocasión, al de los primeros, que he tenido la oportunidad de avanzar, en forma parcial, en otros espacios.

\section{Descartes y Gassendi. Dos rutas fundadoras de la Modernidad filosófica}

En las Meditaciones metafísicas Descartes reconoce la importancia del diálogo con sus diversos objetores del modo siguiente: "[R]uego encarecidamente a los lectores que no formen ningún juicio de estas meditaciones, hasta no haber leído con atención todas estas objeciones y las correspondientes respuestas" (A/T, VII, Medit. 10) (VP, 11).

A pesar de esta recomendación, Descartes instruyó al editor Claude Clerselier para que omitiera, en la versión francesa de las Meditaciones (1647), ${ }^{6}$ la quinta serie de objeciones, escritas por Pierre de Gassendi.

universales, tanto de las que son independientes de los particulares como de las que son dependientes de éstos; por ejemplo, los casos de Descartes y Gassendi, respectivamente (Bolton 1998, pp. 178-195).

${ }^{6}$ Clerselier no accedió a la petición de Descartes, lo que explica él mismo de la manera siguiente: "me pidió que omitiera las quintas objeciones, que razones particulares lo obligaban a quitar de la nueva edición que él quería hacer de sus 
Para justificar su decisión, Descartes explica que le parecieron muy largas y poco importantes, y continuamente desacredita a su crítico por considerar que éste no adoptó una verdadera actitud filosófica al tratar de rebatirlo: "[E]s cierto que no tanto habéis usado las razones de un filósofo para refutar mis opiniones, cuanto los artificios de un orador para eludirlas" (ALQ, II, 788) (VP, 277). ${ }^{7}$ Descartes no sólo está decepcionado de la calidad de los argumentos de su objetor, también percibe que Gassendi recurre a un tono agresivo y áspero que no favorece el diálogo. Por ello le comenta a Mersenne lo siguiente:

Verá que he hecho todo lo que he podido para tratar al señor Gassendi honorable y dulcemente; pero él me ha dado muchas ocasiones para menospreciarlo y para hacerle ver que no tiene el sentido común ni la disposición para razonar. (A/T III Correspond., 388-389, 23 de junio de 1641) ${ }^{8}$

Pero Descartes señala la principal razón de este "diálogo de sordos" - según la frecuente calificación que le otorgan algunos analistas- en forma certera: su interlocutor contraviene de manera continua sus argumentos porque éstos " $[n]$ o concuerdan con la opinión que de antemano usted [Gassendi] ha concebido de la naturaleza de las cosas" (ALQ, II, 829-3; las cursivas son mías). ${ }^{9}$

Es importante subrayar que, en efecto, y como Descartes lo advirtió, en el debate con su detractor se confrontan dos rutas del pensamiento fundadoras de la Modernidad filosófica, que adoptan supuestos ontológicos encontrados y, por ende, promueven consecuencias epistemológicas divergentes en el marco histórico común del problema de encontrar una respuesta ante el escepticismo radical $^{10}$ que permitiese

Meditaciones en francés, tal como lo puede testificar la advertencia que él ha hecho introducir aquí en lugar de ellas. Pero luego, habiendo considerado que estas objeciones provenían de la pluma de un hombre reputado por su gran saber, he considerado que sería conveniente que ellas fuesen vistas por todos, y me ha parecido bien traducirlas, por temor a que se pensase que el señor Descartes había querido que se las omitiera porque no había podido responderlas" (A/T IX Medit., 200-201) (JAD, 528).

${ }^{7}$ Las traducciones de la versión de F. Alquié de las obras de Descartes (CEuvres philosophiques) son mías, salvo que se señale otra cosa.

${ }^{8}$ Las traducciones de la correspondencia de Descartes con Mersenne son mías, a menos de que se indique otra cosa.

${ }^{9}$ Descartes a Gassendi, Respuesta a las Quintas Objeciones.

${ }^{10}$ De acuerdo con Richard Popkin, "[a] finales del siglo XVI y comienzos del XVII fue notable la influencia del resurgimiento del pirronismo antiguo en varios campos del quehacer intelectual" (Popkin 1983, p. 115). Este tema se aborda en particular en el capítulo IV, "La influencia del nuevo pirronismo" (Popkin 1983, pp. 115-143). 
fundamentar el avance del conocimiento en el proyecto de la nueva ciencia. Pasemos ahora a la revisión de algunos aspectos centrales de esta discusión.

El tono burlón y desafiante de Gassendi en sus objeciones a las meditaciones cartesianas, según lo hace notar Alquié, se incrementa a lo largo de la interlocución. Cortés y cauto en el inicio de las mismas, incluso asegura lo siguiente: "[P] ropongo [estos motivos de duda y dificultades] sólo como algo que no va contra las materias de que tratáis y cuya demostración habéis emprendido, sino [solamente] contra el método y las razones de que usáis para demostrarlas" (ALQ, II, 706) (VP, 208). Sin embargo, ya en sus objeciones a la primera meditación, Gassendi manifiesta desdén por el planteamiento cartesiano, que pretendía en esos pasajes "tocar fondo" en el camino de la duda mediante la "duda hiperbólica" como parte de su conocida estrategia para remontarla. $\mathrm{Al}$ respecto, Gassendi reclama:

Digáis lo que digáis, nadie creerá que vos creéis que no hay nada cierto en lo que habíais sabido hasta ahora, y que eso os ha sido impuesto de continuo por los sentidos, o el sueño, o Dios, o un genio maligno. ¿No habría sido más propio de la honestidad filosófica y del amor a la verdad el decir las cosas sencillamente, de buena fe, y tal como son, en vez de recurrir - como podría objetárseos- a todo ese artificio, a la invención de esas ilusiones y la maquinación de esos rodeos? (ALQ, II, 708) (VP, 208-209)

Como se observa, el reclamo de Gassendi intenta adoptar en forma deliberada el tono de "un sano sentido común" con el cual se ridiculiza la propuesta cartesiana por el acento burlón que adopta el objetor. ${ }^{11}$ Descartes, por su parte, responde con energía y sequedad:

[Q] uien dice que eso [considerar falsas todas las cosas] es recurrir a artificios, inventar ilusiones y maquinar rodeos, afirmando que ello es impropio de la honestidad filosófica y el amor a la verdad, muestra bien a las claras

${ }^{11}$ Gassendi también argumentó contra las respuestas de Descartes a las quintas objeciones en la Disquisitio metaphysica de 1644. Ahí examina los planteamientos cartesianos de manera amplia y detallada; por ejemplo, contra la duda hiperbólica explica la imposibilidad de que el espíritu pueda liberarse de todo prejuicio, pues nuestra memoria lo impediría: "De inicio, porque la memoria, siendo como el tesoro de los juicios que hemos formulado previamente y que son depositados en ella, no puede ser borrada a nuestra voluntad" (Gassendi 1962, pp. 36-37). La Disquisitio es testimonio de que uno de los aspectos que revelan la importancia de la discusión de Descartes y Gassendi es su fructífera secuela. 
que es él quien no quiere usar de la honestidad filosófica ni de razones, sino adornar las cosas con los afeites y colores de la retórica. (ALQ, II, 790) (VP, 279)

El proceder de Gassendi, insensible a la sofisticada estrategia cartesiana, se explica si consideramos sus premisas de partida, a saber, entre otras, que, en vista de las limitaciones inherentes al conocimiento humano, es menester aplicarlo al servicio de las cosas que son útiles para la vida. En este contexto, Gassendi rechaza el sentido metafísico de la estrategia que conducirá a Descartes al descubrimiento del cogito. De este modo, ya desde las objeciones dirigidas a la primera meditación Gassendi manifiesta su resistencia a comprender el proyecto cartesiano. $^{12}$

Hay una larga historia detrás de esa renuencia. El antagonista de Descartes se puede ubicar en la ruta de pensamiento cultivada por Ockham (1280/8-1349), quien sólo aceptó dos tipos de entidades existentes: Dios y el mundo creado, poblado de cosas contingentes y cuyo conocimiento excluye postular nexos causales necesarios. ${ }^{13}$ Por otra parte, y consecuente con su empirismo, Ockham insistía en que las premisas básicas de la ciencia debían derivarse de la experiencia y, dado que tales premisas no podían implicar relaciones necesarias entre

\footnotetext{
${ }^{12}$ Leonel Toledo ha aportado elementos importantes para argumentar que el rechazo de Gassendi a las tesis de Descartes no se debe a que no haya comprendido sus tesis: "[L]a oposición de Gassendi a Descartes no se explica porque aquél no haya entendido la profundidad de la tesis del otro. Más bien, los principios con los que cada uno define el quehacer filosófico son opuestos y, así, es de esperar que para el humanista el afán cartesiano sea, de entrada, irrealizable.” En este recomendable ensayo, Toledo expone una visión amplia de la filosofía de Gassendi que permite recuperar su pensamiento más allá de la mera discusión que entabla con Descartes (Toledo Marín 2013, p. 67). Como mencioné aquí, se trata de una discusión que parte de principios filosóficos incompatibles.

${ }^{13} \mathrm{Cfr}$. "Uno modo dicitur aliquid necessarium, perpetuum et incorruptibile quia per nullam potentiam potest incipere vel desinere esse. Et sic Deus est perpetuus, necessarius et immortalis" (De un modo se dice que es necesario, perpetuo e incorruptible lo que no puede, de alguna manera, comenzar o dejar de ser. En ese sentido, sólo Dios es necesario, perpetuo, inmortal), Summa totius logicae, Oxoniae 1675 (III, II, c. 5, p. 334), cit. en Baudry 1958, p. 170. Al respecto, Gordon Leff comenta que "necesario" para Aristóteles es lo que no se puede saber de otra manera y se aplica a las cosas rerum natura, tal como la razón del eclipse de luna (Leff 1975, p. 277). En cambio, para Ockham, desde su enfoque cristiano, sólo Dios es necesario y, al depender de su voluntad, todo lo demás es contingente. Para profundizar al respecto se recomienda el capítulo 4 del erudito estudio de Leff 1975 titulado "Propositions, Syllogisms and Demonstrations" (pp. 239-317).
}

Revista de Filosofía Diánoia, vol. 65, no. 84 (mayo-octubre de 2020) e-ISSN: 1870-4913 • DOI: https://doi.org/10.22201/iff.18704913e.2020.84.1613 
causas y efectos, debían expresarse como enunciados condicionales o hipotéticos. En esta perspectiva, el carácter del conocimiento humano debía ser el de la contingencia y esta convicción, aunada a la idea nominalista de que lo que no es observable no es real, preñó la orientación fundamental del pensamiento británico, pero también, como en el caso de Gassendi, de una parte de la reflexión continental. Así, la influencia de Ockham dio lugar a una tendencia muy difundida a aceptar el empirismo como el fundamento de todo aquello que el conocimiento humano era capaz de alcanzar, pero también dio paso a la concepción de que las entidades y formas inobservables debían considerarse irreales e incapaces de erigirse como auténticos mecanismos ontológicos explicativos. Por ello, es posible afirmar con Edward Grant que: "El empirismo y el rechazo de la realidad de lo inobservable se convirtieron en rasgos característicos de la modalidad nominalista en la ciencia y en la filosofía" (Grant 1983, p. 64).

Veremos a continuación que, en la discusión que analizo, afloran todos estos rasgos de los que parten las premisas gassendianas, a saber:

1. Los elementos ontológicos explicativos excluyen las entidades inobservables; ${ }^{14}$

2. el auténtico conocimiento ha de tener como respaldo la realidad observable, opinión de la que se deriva que concebir algo trae aparejada, inevitablemente, su imagen; y que,

3. al aceptar como único origen del conocimiento el empírico, todas nuestras nociones, incluso las de carácter matemático, no son sino meras generalizaciones de lo observado.

En suma, el conocimiento humano, contingente y limitado, se aloja por completo en el terreno de lo aproximativo y lo probable, panorama que le impide a Gassendi aceptar los planteamientos cartesianos de las Meditaciones metafísicas a los que volveré enseguida.

${ }^{14}$ Como Descartes, Gassendi supone que sólo podemos percibir apariencias. Sin embargo, a diferencia del filósofo de la Touraine, sostiene que éstas son todo lo que podemos saber, por lo que rechaza el conocimiento de esencias. Leonel Toledo y Samuel Herrera formulan lo anterior del modo siguiente: "[P]ara el objetor de las Meditaciones, el conocimiento de la naturaleza tiene su inicio en el nivel de los datos de los sentidos y, en cualquier caso, la experiencia sensible debe someterse a una especie de 'refinamiento'. Sin embargo, a través de este proceso de depuración jamás lograremos tener acceso a la naturaleza íntima de las cosas o a las sustancias" (Herrera y Toledo 2018, p. 263).

Revista de Filosofía Diánoia, vol. 65, no. 84 (mayo-octubre de 2020) e-ISSN: 1870-4913 • DOI: https://doi.org/10.22201/iifs.18704913e.2020.84.1613 


\section{Gassendi y Descartes ante el conocimiento de las entidades abstractas}

Son varios los pasajes que ponen de relieve las premisas de Gassendi. En relación con el conocido pasaje de la cera (segunda meditación), Gassendi objeta que el sustrato o sostén del color, de la figura, de la capacidad de fundirse de la cera, etc., es incognoscible. Al argumentar en esta dirección, manifiesta su concepción tanto del carácter conjetural de todo conocimiento como la asociación indisoluble que da por sentada entre concebir algo e imaginarlo:

[Si concebimos que] hay alguna cosa que es sujeto de los accidentes y los cambios observados, siempre permanece oculta, y juzgamos sólo por conjetura que debe haber algún sujeto que sirva como sostén o cimiento a todas las variaciones de las que la cera es capaz. [...] Y si pensáis comprender de algún modo qué es esa cosa, decidnos: ¿cómo la concebís? ¿No será como algo extenso y capaz de fundirse? ¿ $[$ [...] acaso no la concebís como dotada de una figura? Y luego, al concebirla de tal manera que os parezca verla, ¿̇no le atribuís algún color, aunque sea oscuro y confuso? [...] y por tanto, vuestra intelección sigue siendo una especie de imaginación. Y si decís que la concebís sin extensión, figura ni color, decidnos honestamente ¿qué es entonces? (ALQ, II, 718-20) (VP, 215-26)

Está claro que Gassendi no puede aceptar el análisis cartesiano de la esencia de la cera; su visión del mundo excluye esta clase de entidades. En efecto, el propósito de Descartes - y que soslaya su objetor- al plantear este experimento mental es el de permitir considerar las notas conceptuales del concepto de cuerpo y las propiedades que están contenidas analíticamente en él (cfr. Wilson 1990, p. 133) para examinar, como lo hace en la sexta meditación, la idea de extensión, aprehensible a través de las propiedades métricas del cuerpo.

En contraste, Gassendi insiste en que la idea de la cera ha de ser una imagen, o nada en absoluto. A este respecto, coincido con Vidal Peña, quien observa que esta consideración anuncia el tono de la crítica berkeleyana a las "ideas generales abstractas". Como corresponde a la tradición nominalista, ésta sólo acepta ideas particulares, por lo que las "ideas generales" sólo existen al aumentar la extensión de las ideas particulares; empero, las ideas generales abstractas no existen. ${ }^{15}$

${ }^{15}$ En efecto, Gassendi acepta el rechazo del nominalismo tradicional a todo referente ontológico del universal (Universale in re). La presencia del universal en el alma se produce a partir de las cosas singulares, según lo expone en la lógica del Syntagma philosophicum, en los libros del tomo II, dedicados a las facultades del conocimiento y a la "aprehensión simple" de las imágenes como la primera de 
Así, Peña afirma: "La bipartición de la realidad en entidades físicas y mentales (con exclusión de un "reino ideal" no reductible a los otros dos) preside dicha crítica" (VP 451, n. 163).

Esta orientación gassendiana se confirma con su rechazo al carácter que Descartes atribuye a la "cosa que piensa". De acuerdo con Gassendi, no basta con afirmar "soy una cosa que piensa"; al respecto, responde a Descartes:

[E]s preciso que os examinéis a vos mismo como si fuese una cuestión de química, de manera que podáis revelarnos el interior de vuestra sustancia. Y cuando lo hayáis hecho así, nos tocará examinar si sois mejor conocido que ese cuerpo, cuya naturaleza nos manifiestan tan claramente la anatomía, la química, tantas artes diferentes y tan diversas experiencias. (ALQ, 723) (VP, 223)

La crítica de Gassendi manifiesta la premisa de que si la sustancia pensante es algo, entonces es reductible a un cuerpo. Concuerdo en esto con Alquié, quien observa que Gassendi parece buscar aquí el conocimiento del alma considerada un objeto material, un conocimiento procedente de un análisis análogo al análisis químico:

[E]n la afirmación cartesiana: "Soy una cosa que piensa", ve una banalidad comparable a "El vino es un líquido blanco o rojo". No percibe que toda la originalidad de Descartes ha sido, precisamente, la de descubrir el alma como principio de conocimiento, principio inanalizable, por su imposibilidad de ser reducido a una cosa material. (ALQ, II, 723, n. 2)

Sin embargo, es en las objeciones dirigidas a la quinta meditación donde la orientación empirista-nominalista de Gassendi en relación con los objetos matemáticos se hace patente. En el conocido pasaje que examina la naturaleza de las "verdades inmutables", Descartes señala:

sus etapas. Ésta se explica funcionalmente por los trazos que forman los movimientos de los "espíritus animales" que resultan de las percepciones de los sentidos. Estos pliegues o líneas de pliegues que dan lugar a las imágenes en el cerebro sólo pueden ser, desde luego, singulares, pues éstas no podrían aprehender universales. Entonces, ¿cómo son posibles los universales como "hombre", "humanidad", etc.? Estos universales sólo lo son de similitude, adquiridos por la comparación de imágenes parecidas (cfr. Bloch 1971, pp. 138-139). Berkeley, en la misma ruta heredera del nominalismo, acepta la existencia de ideas generales, pero sólo como significados de palabras pues toda idea, si se considera en sí misma, es particular: "[N]o niego en absoluto la existencia de ideas generales: lo que no puedo admitir es que existan ideas generales abstractas", Principios del conocimiento humano, § XII, p. 39. 
[H]allo en mí infinidad de ideas de ciertas cosas [...] que no pueden ser estimadas como una pura nada, aunque tal vez no tengan existencia fuera de mi pensamiento, y que no son fingidas por mí, aunque yo no sea libre de pensarlas o no; sino que tienen naturaleza verdadera e inmutable. Así, por ejemplo, cuando imagino un triángulo, aun no existiendo una tal figura en ningún lugar fuera de mi pensamiento, y aun cuando jamás la haya habido, no deja por ello, de haber cierta naturaleza, o forma, o esencia de esa figura, la cual es inmutable y eterna, no ha sido inventada por mí y no depende en modo alguno de mi espíritu; y ello es patente porque pueden demostrarse diversas propiedades de dicho triángulo - a saber, que sus tres ángulos valen dos rectos, que el ángulo mayor se opone al lado mayor y otras semejantes-. (A/T VII, 64) (VP, 54)

$\mathrm{Al}$ respecto, Gassendi adopta la postura que se deriva de su rechazo a la existencia de las nociones que constituyen el "tercer reino", al que aquí apela Descartes. No hay más que entidades físicas (materiales) y las reflexiones que la mente sobre ellas. Por ello, lejos de aceptar que la idea del triángulo contiene de manera necesaria sus propiedades, Gassendi opone su idea del triángulo como una noción construida por el intelecto, resultado de una mera generalización empírica:

[E]l espíritu lo ha formado, partiendo de los triángulos materiales que los sentidos le han permitido percibir, y cuyas ideas ha reunido para hacer con ellas una idea común, al modo en que acabo de explicar tocante a la naturaleza del hombre.

Por ello, tampoco hace falta imaginar que las propiedades que, según se demuestra, pertenecen a los triángulos materiales, les convengan por haber sido tomadas de ese triángulo ideal y universal; pues al contrario, aquéllos son los que verdaderamente tienen en sí esas propiedades y no éste, sino sólo en cuanto que el entendimiento se las atribuye. (ALQ, 759) (VP, 256)

Como se observa, Gassendi supone que los teoremas que explicitan las propiedades de las figuras tienen un origen empírico, lo cual revela la ausencia de una reflexión específica sobre el carácter de necesidad de las entidades matemáticas (cfr. VP, 453, n. 190). Tal ausencia se deriva de que, como indiqué, para Gassendi no hay esencias eternas ni ideas innatas. Todas las ideas nos advienen, son abstracciones de las cosas que nos presenta la experiencia y, por ende, poseen una naturaleza sólo contingente. ${ }^{16}$

${ }^{16}$ Gassendi aborda el problema los universales como derivados de las ideas sensi- 
La postura opuesta de Descartes es muy clara. Las ideas matemáticas no provienen de una mera generalización empírica, sino que:

[P]or lo que toca a las esencias que conocemos de modo claro y distinto, como las del triángulo o cualquier otra figura geométrica, me será fácil hacer que reconozcáis que las ideas que de ellas tenemos no han podido ser obtenidas de las ideas de las cosas singulares. (ALQ, 827) (VP, 299)

Considerarlo así es lo propio de la opinión del sentido común, incapaz de reparar en las razones de cuño filosófico. La respuesta de Descartes intenta hacer notar a su objetor la imposibilidad de que las entidades matemáticas se originen en los sentidos:

$[\mathrm{N}]$ o estoy de acuerdo en que las ideas de tales figuras hayan sido alguna vez objeto de nuestros sentidos, según se cree vulgarmente. Pues aunque, sin duda, puede haber en el mundo algunas que sean tal como los geómetras las consideran, niego que las haya a nuestro alcance, salvo, acaso, algunas tan pequeñas que no causan impresión alguna sobre nuestros sentidos; pues están compuestas ordinariamente por líneas rectas, y pienso que jamás ha impresionado nuestros sentidos parte alguna de una línea que fuera realmente recta. $Y$ así, cuando a través de una lente miramos las que nos habían parecido más rectas, las vemos irregulares, y onduladas. Por tanto, cuando en nuestra niñez hemos visto por vez primera una figura triangular trazada sobre un papel, esa figura no ha podido enseñarnos la manera de concebir el triángulo geométrico, pues no lo representaba mejor de cómo representa un mal lápiz una imagen perfecta. (ALQ, II, 829-30) (VP, 300)

El origen extraempírico de las entidades matemáticas —extensible a otras entidades abstractas entre las que se encuentran, por ejemplo, las lógicas - se sustenta en la anterioridad de la constitución del concepto, irreductible a su aprehensión sensible:

Mas como la idea verdadera del triángulo estaba ya en nosotros, y nuestro espíritu podía concebirla más fácilmente que la figura, más compuesta de

bles en Institutio logica, que forma parte de su Syntagma philosophicum. Ahí explica que, en vista de que todas las ideas que provienen de los sentidos son singulares, las ideas generales deben constituirse desde las singulares a través de ciertas operaciones de la mente. Con ideas de Epicuro, Gassendi explica lo anterior en su Institutio como resultado de las operaciones de unión o de separación que efectúa la mente. Cfr. Bolton 1998, p. 190. El ensayo de Bolton es muy recomendable para profundizar en este aspecto de la filosofía de Gassendi.

Revista de Filosofía Diánoia, vol. 65, no. 84 (mayo-octubre de 2020) e-ISSN: 1870-4913 • DOI: https://doi.org/10.22201/iifs.18704913e.2020.84.1613 
un triángulo pintado, por eso, al ver dicha figura compuesta no la hemos concebido a ella misma, sino más bien al verdadero triángulo. (VP, 300) (ALQ, II, 829-30)

De acuerdo con Descartes, el "verdadero triángulo" es el que se concibe con el intelecto, del cual se desprenden analíticamente sus propiedades. Por ello, la constitución de las entidades matemáticas obedece al orden y estructura de su necesidad interna, la cual es imposible de derivarse de las impresiones sensibles. ${ }^{17}$

La querella entre Descartes y Gassendi se inició en las Meditaciones metafísicas (1641) pero, como ya mencioné, este último contestó a las respuestas de Descartes en una obra específica, la Disquisitio metaphysica (1644), y Descartes hizo lo propio en La carta del señor Descartes al señor Clerselier (12 de enero 1646). Aquí sólo he pretendido abordar el arranque de esta fructífera discusión -que se prolongaría en otros espacios- y, en particular, la parte que se refiere a la naturaleza de las entidades abstractas. En el contexto de las Meditaciones, la polémica de las quintas objeciones continúa en las sextas, que abordaré a continuación.

\section{Mersenne, el objetor anónimo de Descartes}

Marin Mersenne, el más frecuente corresponsal de Descartes y también agente activo de vinculación entre los científicos de su tiempo, defendió respecto del tema que me ocupa una postura afín a la de Gassendi. En vano buscaremos en la obra de Mersenne alguna crítica explícita dirigida a su admirado y estimado amigo René Descartes sobre el tema que

${ }^{17}$ Este trabajo se centra en la discusión en torno a la irreductibilidad (o no) de las entidades abstractas a procesos empíricos, por lo que aquí no se aborda el tema del innatismo que se suele atribuir a Descartes. Al respecto, deben considerarse las palabras del propio Descartes: "Cuando digo [...] que una idea ha nacido con nosotros, o que está impresa naturalmente en nuestras almas, no quiero decir que esté siempre presente a nuestro pensamiento: si así tuviera que ser no habría ninguna de este género. Sólo quiero decir que en nosotros mismos reside la facultad de producirla" AT IX/147 (VP, 153). Por ello, no es exacto hablar de innatismo en Descartes sin mayores precisiones. En cuanto a las verdades o conocimientos matemáticos, Descartes no los considera innatos, sino sólo gérmenes o simientes de ellos: "[C]iertas semillas de verdades que están naturalmente en nosotros" AT VI, Discurso, 64 (GQA, 46). Al respecto, Élie Denissoff señala: "Descartes se defiende de las acusaciones contra el innatismo. Explica que por "innato" no entiende más que una facultad de tener en sí ciertas ideas, o una disposición para concebirlas" (Denissoff 1953, p. 14). 
analizo en estas páginas. Como Descartes, el padre mínimo cultivó las matemáticas, y dedicó amplios volúmenes al desarrollo de ese tema. En ellos se abrieron espacios para la reflexión acerca de la naturaleza ontológica de las entidades abstractas que nos permiten conocer la postura - que discrepa de la cartesiana - de este autor la cual, en el contexto de las Meditaciones, se presentó sobre todo en las sextas objeciones. ${ }^{18}$

De acuerdo con Mersenne, la certeza del conocimiento matemático no difiere de la que se obtiene en la física, en el conocimiento del mundo natural. En efecto, no nos es posible saber cómo es realmente éste, del que sólo conocemos sus efectos; las cualidades últimas de las cosas se nos escapan. Esta posición, que lo ubica en la línea de la negativa de Gassendi a la posibilidad de conocer sustancias, se expresa en los siguientes pasajes decisivos:

¿Podemos saber algo cierto en la Física o en las Matemáticas? Es cierto que desconocemos la mayor parte de las cosas de la naturaleza, [igualmente] no conocemos una sola verdadera razón de todo lo que ella contiene, ni de lo que ella produce; [...] no sabemos la verdadera razón de los efectos que vemos muy claramente y nos sujetamos a su uso. (M. Mersenne, Questions inouyës, pp. 69-71, cit. en Lenoble 1943, p. 347) ${ }^{19}$

En el panorama descrito por Mersenne, dado que el terreno asequible al conocimiento no es sino el de los efectos naturales y no el de las causas últimas que los producen -esencias inalcanzables para el conocimiento humano-, el uso práctico que hacemos de los primeros constituye el auténtico ámbito epistémico de la ciencia. ${ }^{20}$ Una situación paralela

${ }^{18}$ Mersenne también presentó las segundas objeciones, "Recogidas por el R.P. Mersenne de la boca de diversos teólogos y filósofos", tal como se advierte en la obra misma.

${ }^{19}$ Las traducciones que se presentan de Lenoble 1943 son mías.

${ }^{20} \mathrm{He}$ expuesto en otro lugar que: "El rechazo a los sistemas de filosofía anclados en una base metafísica sustancialista, describe una ruta fundamental de las primeras obras de Marin Mersenne, periodo que abarca de 1623 (Quaestiones in Genesim) a 1634, año de publicación de sus cinco tratados tempranos (Questions inouyës, Questiones harmoniques, Les Questiones théologiques, Les Mechaniques de Galillée, Les Preludes de l'Harmonie Universelle). A pesar de su cercanía con René Descartes —su principal corresponsal-y de coincidir con éste en numerosos temas, Mersenne se mantuvo alejado de la concepción de que es posible conocer esencias o sustancias de las cosas. En cambio, propone un peculiar empirismo que, por una parte, rompe con el escepticismo radical; por otra, mantiene un punto de vista conciliador con relación al silogismo aristotélico y, de manera principal, defiende que el conocimiento humano es factible, pero dentro de los límites acotados por las capacidades 
alcanzan las matemáticas y la metafísica misma, que así resultan ser meras configuraciones de la imaginación y del intelecto. Al respecto, Mersenne se pregunta:

¿En cuanto a las matemáticas, sabemos siquiera lo que es la cantidad? [...] Las únicas matemáticas legítimas son aquellas de lo posible [...] puede decirse que las matemáticas puras son una ciencia de la imaginación, o de la pura inteligencia, como lo es la Metafísica. (M. Mersenne, Questions inouyës, pp. 69-71, cit. en Lenoble 1943, p. 347)

La inasequibilidad de las sustancias y el carácter instrumental del conocimiento son, según Mersenne, las dos caras de la misma moneda. En este texto de 1634, Questions inouyës, ni las matemáticas ni la metafísica alcanzan el conocimiento de las sustancias.

No obstante, casi diez años antes, en su obra enciclopédica La verité des sciences de 1625, Mersenne ya exponía esta concepción. Del estudio científico de los fenómenos, señala el padre mínimo, "[N]o hace falta pensar que podamos penetrar [en su] naturaleza, [ni sabemos] lo que pasa en el interior de ellos, pues, [de dichos fenómenos] nuestros sentidos, sin los cuales el entendimiento nada puede conocer, no ven sino lo que es exterior" (Mersenne 1969, p. 212). ${ }^{21}$ Para Mersenne, la sujeción del entendimiento a los sentidos acota el ámbito de aquél: producir un conocimiento de carácter hipotético, pues los mismos efectos naturales pueden explicarse a partir de diversas causas. Así, en la misma obra de 1625, señala que son muchas las concepciones "que podemos tener de todos los fenómenos posibles, por las cuales las acciones de las cosas naturales pueden explicarse" (Mersenne 1969, p. 213).

Entonces, en el marco empirista e instrumentalista de Mersenne ¿existen, como para Descartes, "verdades eternas"? Éste es uno de los temas centrales de las sextas objeciones, propuestas a las Meditaciones metafísicas de Descartes por un grupo anónimo de filósofos y geómetras entre los cuales, como veremos, se puede suponer la presencia de Mersenne.

Estos geómetras y filósofos interrogan a Descartes a propósito de su concepción de verdades eternas como "el todo es mayor que la parte", "los contradictorios no pueden estar juntos", "la suma de los ángulos internos del triángulo es igual a dos ángulos rectos" o "dos veces cuatro son ocho". Si éstas son en realidad inmutables y eternas - preguntan del raciocinio, las cuales impiden el acceso al conocimiento de sustancias" (Velázquez Zaragoza 2018, pp. 247-248).

${ }^{21}$ Las traducciones de las obras referidas de Mersenne son de mi autoría. 
los objetores-, ¿cómo pueden depender de Dios? Es decir, "[¿Dios] habría podido hacer que la naturaleza del triángulo no existiera? ¿O que no fuese cierto, desde toda la eternidad, que dos por cuatro fuesen ocho? ¿O que un triángulo no tuviera tres ángulos?” (A/T IX, 222) (VP, 319). En suma, ¿La voluntad de Dios podría alterar estas verdades? Si no es así, entonces — siguen los objetores-, estas verdades no parecen depender de Dios, lo cual es manifiestamente inaceptable. El planteamiento acerca de la naturaleza de las verdades eternas queda reducido a estas opciones: "[N]o dependen más que del entendimiento solo, cuando piensa, o dependen de las cosas mismas, o bien son independientes; ya que no parece posible que Dios haya hecho de manera que alguna de ellas no existiese desde toda la eternidad" (A/T IX, 222) (VP, 319).

Esta objeción señala la dificultad en la que Descartes parece haber caído. Si las verdades lógicas y matemáticas, como sostiene, son eternas ¿qué papel desempeña la voluntad de Dios en ellas? Por supuesto, si no ha de cambiarlas, entonces ile imponen un coto a la voluntad de Dios? Según el planteamiento cartesiano, tal como lo exponen los objetores, el estatus de estas verdades reconoce las siguientes posibilidades:

1. Que sólo dependan del entendimiento, es decir, que sean confecciones mentales y, por ende, fruto de la intelección humana.

2. Que sean dependientes de las cosas mismas; que resulten de algún proceso de abstracción a partir de las cosas.

3. Que sean del todo independientes de la voluntad de Dios y poseedoras de una existencia eterna. ${ }^{22}$

La respuesta de Descartes descalifica las tres opciones planteadas. Ante todo, señala que la inmensidad de Dios imposibilita que haya algo que no dependa de Él, por lo cual se cancela la tercera posibilidad. Asimismo, se eliminan las otras dos opciones porque, según explica, "[N]o hay por qué pensar que las verdades eternas dependen del entendimiento humano, o de la existencia de las cosas, sino tan sólo de la voluntad de Dios que, como supremo legislador, las ha ordenado y establecido desde toda la eternidad" (A/T IX, 236) (VP, 333). Descartes no ve problema alguno en aceptar tanto la perfección divina plasmada en su creación, y por la cual ha establecido las verdades eternas, como su omnipotencia, la cual no se vulnera por este hecho. El acuerdo entre

${ }^{22}$ Cfr. Velázquez Zaragoza 2010, pp. 184 y ss.

Revista de Filosofía Diánoia, vol. 65, no. 84 (mayo-octubre de 2020) e-ISSN: 1870-4913 • DOI: https://doi.org/10.22201/iifs.18704913e.2020.84.1613 
perfección y omnipotencia pertenece a la esfera de lo que "ni comprendemos, ni vemos que deberíamos comprender" (A/T IX, 236) (VP, 333). De este modo, nos dice Descartes, es un despropósito intentar desentrañar, en términos de la causalidad humana, el ámbito de la voluntad divina y su concordancia con el establecimiento de las verdades eternas, impronta de su perfección.

Pero ¿dónde aparece Mersenne en este escenario? La presencia del padre mínimo en el grupo de objetores se trasluce cuando éste parece argumentar, como veremos enseguida, en favor de la primera de las alternativas; es decir, al defender que las verdades en cuestión son meras confecciones mentales. Esta opción tiene la ventaja de que, además de no comprometer la acción voluntaria de Dios - trasunto de las observaciones de los objetores-, se instala en el marco antes descrito, empirista e instrumentalista. Al descartar la segunda opción, Mersenne se aleja de la solución atribuida a Aristóteles, quien supondría que el origen de este género de verdades es el resultado de un proceso de abstracción a partir de las cosas.

En relación con el carácter de las entidades abstractas dependiente del entendimiento humano, el padre mínimo, en su ya mencionada obra de 1625, La vérité des sciences, afirma:

[B] asta que las ciencias y todas sus nociones sean seres de razón para que sean verdaderas y en conformidad con los objetos exteriores y con sus propiedades: basta que la línea o el círculo que concibo y aquél sobre el que los matemáticos discurren sean totalmente concebidos, para que todo lo que de ellos se ha dicho sea verdadero. Por lo que podemos concluir que todas las ciencias son obras de la sola razón. (Mersenne 1969, pp. 275-276)

Si es así, no hay por qué considerar eternas estas verdades; son, simplemente, entes creados por el intelecto y que confirman su uso instrumental. Esta conclusión parece ratificarse en el siguiente pasaje, en el que se señala que las verdades de las ciencias, incluidas las de las matemáticas,

[R]esiden en la razón, sin la cual no pueden subsistir: no importa si son relativas o absolutas, o si se relacionan con las cosas exteriores, o no, pues basta que sirvan de gran camino real al entendimiento para viajar por el cielo, por la tierra y por todas las criaturas pasadas, presentes, futuras o posibles, y que toda suerte de experiencias confirmen su verdad; pues jamás dejará de encontrarse que dos veces dos hombres sean cuatro hombres, según la idea que la razón había concebido. (Mersenne 1969, p. 277) 
Por lo anterior, de acuerdo con Mersenne la solidez interna de estas verdades, que confirma su aplicación empírica, basta para ver en ellas un instrumento clave para la edificación de la ciencia en la aurora de la Modernidad. No es preciso exigirle más.

En su propósito de construir una nueva ciencia, el sacerdote francés busca alejarse de la tradición escolástica, lo que se corrobora en las críticas que dirige al Estagirita en el terreno de la física:

Aristóteles se ha equivocado, en primer lugar, cuando ha dicho que el mundo era eterno, en el libro primero de su Física, capítulo cuatro [...] ha querido probar las cosas que pertenecen a la Física por las Matemáticas, pues viendo que el número matemático era infinito en potencia [...] ha concluido que el mundo era eterno e infinito, aunque él sabía que la grandeza sensible no puede estar compuesta de principios inteligibles, tal como lo son los principios de la matemática. (Mersenne 1969, pp. 119-120)

Por lo tanto, ni la eternidad ni la infinitud potencial pueden atribuirse al mundo físico; son propias de las entidades matemáticas como principios meramente inteligibles, seres de razón. La concepción de Mersenne es la de un científico piadoso que concilia el conocimiento con las verdades de la religión cristiana y, de ese modo, las entidades matemáticas no pueden ser sino meros constructos racionales.

\section{Conclusión}

La importancia de las matemáticas en la edificación de la nueva ciencia está fuera de toda duda. Baste mencionar el impacto en el siglo XVII del desarrollo de la óptica geométrica que le permitió a Descartes afinar las leyes de la refracción de la luz y proponer una explicación correcta del arco iris, entre otros tantos logros de las matemáticas aplicadas durante dicho siglo. Como se sabe, el gran logro de Descartes en esta área fue su geometría de coordenadas, una aportación que lo colocó en un sitio muy elevado en la historia de las matemáticas.

Sin embargo, menos conocida es su contribución a la discusión de la naturaleza ontológica de las matemáticas, su defensa de las verdades eternas, tema que dividió a los promotores de la ciencia nueva en los dos grandes bandos que he mencionado. Esta página histórica de la disputa entre los partidarios del irreductibilismo y sus opositores se escribió en el contexto de la búsqueda de un fundamento epistemológico que fuera capaz de sostener el edificio de la ciencia de la naturaleza en desarrollo. Tanto Descartes como sus objetores buscaban combatir

Revista de Filosofía Diánoia, vol. 65, no. 84 (mayo-octubre de 2020) e-ISSN: 1870-4913 • DOI: https://doi.org/10.22201/iifs.18704913e.2020.84.1613 
la amenaza que representaban las tendencias escépticas que cobraron fuerza durante la Modernidad temprana. La ciencia verdadera debía afianzar sus frutos sobre bases sólidas. Para Descartes, los cimientos tenían que ser realmente inamovibles para garantizar la solidez de la edificación; de ahí la urgencia de disponer de verdades eternas. En contraste, de acuerdo con Gassendi y Mersenne, para atacar al pirronismo era suficiente contar con una ciencia instrumental, aproximativa, fincada sobre bases meramente hipotéticas. De esta forma, se ubicaron en la línea propia del escepticismo moderado al recuperar de manera renovada elementos metodológicos provenientes del nominalismo y del empirismo.

Debe subrayarse que, a diferencia de Descartes, Gassendi y Mersenne eran hombres religiosos; en el caso de este último, su visión es la de un científico piadoso que considera compatibles la fe cristiana con el conocimiento y, más aún, que la ciencia ha de ofrecerse al servicio y para la gloria del Autor de la creación. En estas condiciones, su compromiso con la teología de la tradición cristiana contrasta de manera notoria con la audacia de Descartes, un pensador capaz de proponer un Dios filosófico como garante de las verdades inamovibles. Así, podemos advertir detrás de los grupos en pugna diferentes posiciones metafísicas y epistemológicas, pero también vitales.

Según he mostrado, en el debate de la Modernidad temprana la fundamentación epistemológica que se requería para la erección de la nueva ciencia buscó arraigarse en el terreno ontológico que le proporcionara un mejor sustento, ya inamovible y eterno, o bien perecedero y aproximativo. El ingrediente clave, en cualquiera de los casos, fue el esclarecimiento del papel de las entidades abstractas —aritméticas, geométricas, lógicas- en la metafísica del entramado científico.

Como vimos, la discusión de Frege contra el psicologismo de Mill tiene un antecedente interesante en la discusión del siglo XVII que he analizado. La propuesta cartesiana sostuvo, como después lo haría Frege, la irreductibilidad de las entidades abstractas —en Frege, las leyes de la aritmética- a elementos empíricos. En Descartes, las verdades eternas son inherentes a la operación del intelecto, el cual se constituye según el designio divino, pero éstas no subsisten fuera de la mente humana - una precaución indispensable en vista de sus convicciones teológicas-. Así, si bien no postula la existencia independiente o extramental de estas entidades - como parece establecerlo Frege-, supone, como éste, su carácter necesario.

El bando detractor, que representan aquí Gassendi y Mersenne, se aposta en la línea de Mill en la medida en que defiende el origen empí-

Revista de Filosofía Diánoia, vol. 65, no. 84 (mayo-octubre de 2020) e-ISSN: 1870-4913 • DOI: https://doi.org/10.22201/iifs.18704913e.2020.84.1613 
rico de las entidades abstractas, elaboradas por el entendimiento y que, por ello, sólo aspiran a la certeza hipotética. En contextos problemáticos muy distantes, estos proyectos en disputa representan diferentes versiones de la misma discusión central. Ya en el siglo XVII, o bien más de dos siglos después, la discusión aspira a desentrañar el carácter de la objetividad que cabe esperar de las verdades abstractas. ${ }^{23}$

\section{Referencias bibliográficas}

Obras de René Descartes

A/T CEuvres de Descartes, ed. Charles Adam y Paul Tannery, 11 vols., Léopold Cerf, París, 1996.

ALQ OEuvres philosophiques, ed. Ferdinand Alquié, 3 vols., Garnier, París, 1988.

JAD Meditaciones acerca de la filosofía primera. Seguidas de las objeciones y respuestas, trad. Jorge Aurelio Díaz, Universidad Nacional de Colombia, Sede Bogotá-Facultad de Ciencias Humanas, Bogotá.

VP Meditaciones metafísicas con objeciones y respuestas, intr., trad. y notas Vidal Peña, Alfaguara, Madrid, 1997.

Obras de Pierre Gassendi

1962 Disquisitio metaphysica seu dubitationes et instantiae adversus Renati Cartesii Metaphysica, et responsa. Recherches métaphysiques, ou doutes et instances contre la métaphysique de R. Descartes et ses réponses, ed. y trad. Bernard Rochot, J. Vrin, París.

Obras de Marin Mersenne

1969 La vérité des sciences. Contre les sceptiques ou pyrrhoniens, Friedrich Frommann, Stuttgart/Bad Cannstatt [reproducción facsimilar de la edición de 1625, París].

${ }^{23}$ Agradezco el apoyo de los siguientes proyectos de investigación de la Dirección General de Asuntos del Personal Académico (DGAPA-UNAM) para la realización de este trabajo: IN401517 "Ciencia e imaginación en la filosofía moderna y sus antecedentes"; IN400319 "Epistemologías personales en docentes y su impacto para la enseñanza de la ciencia y de la filosofía" e IN401620 "El papel de la hipótesis en el desarrollo del conocimiento y de la filosofía natural, siglos XVII y XVIII. Antecedentes y prospectiva". Asimismo, debo agradecer al Seminario del Área de Historia de la Filosofía del Instituto de Investigaciones Filosóficas (UNAM) dirigido por Laura Benítez Grobet y José Antonio Robles García (†) en cuyo espacio se gestó, discutió y afinó este ensayo. Gracias también a los cuidadosos dictaminadores de la primera versión de este trabajo por sus atinadas recomendaciones. 
2003 La vérité des sciences. Contre les sceptiques ou pyrrhoniens, ed. y notas Dominique Descotes, Champion, París.

Bibliografía secundaria

Baudry, Léon, 1958, Lexique philosophique de Guillaume D’Ockham. Étude des notions fondamentales, P. Lethielleux, París.

Benítez, Laura y Luis Ramos-Alarcón (coords.), 2018, El concepto de sustancia de Ficino a Descartes, Facultad de Filosofía y Letras-unAm, México.

Berkeley, George, 1974, Principios del conocimiento humano, trad. Pablo Masa, Aguilar, Buenos Aires.

Bloch, Olivier René, 1971, La philosophie de Gassendi. Nominalisme, matérialisme, et métaphysique, Martinus Nijhoff, La Haya.

Bolton, Martha, 1998, "Universals, Essences, and Abstract Entities", en Daniel Garber y Michael Ayers (comps.), The Cambridge History of SeventeenthCentury Philosophy, Cambridge University Press, Cambridge, vol. I, pp. 178211, <https://doi.org/10.1017/CHOL9780521307635.010>.

Denisoff, Élie, 1953, "La Nature de la connaissance mathématique selon Descartes", en Actes du XI ${ }^{\text {eme }}$ Congrès International de Philosophie, vol. XIII, Histoire de la philosophie moderne et contemporaine, North-Holland Publishing Company/E. Nauwelaerts, Ámsterdam/Lovaina, pp. 13-17.

Frege, Gottlob, 1972, Conceptografía. Los fundamentos de la aritmética. Otros estudios filosóficos, trad. Hugo Padilla, Instituto de Investigaciones FilosóficasUNAM, México [1a. ed.: Begriffsschrift, eine der arithmetischen nachgebildete Formelsprache des reinen Denkens, 1879; Die Grundlagen der Arithmetik, eine logisch-mathematische Untersuchung ueber den Begriff der Zahl, 1884].

Frege, Gottlob, 1996, "El pensamiento. Una investigación lógica", trad. Carlos Pereda, en Pensamiento y lenguaje. Problemas en la atribución de actitudes proposicionales, comp. e intr. Margarita M. Valdés, Instituto de Investigaciones Filosóficas-UnAm, México [1a. ed.: Der Gedanke, ein Beiträge zur Philosophie des deutschen Idealismus, I, 1918-1919, pp. 58-77].

Grant, Edward, 1983, La ciencia física en la Edad Media, trad. Adalberto Weinberger, Fondo de Cultura Económica, México [1a. ed.: Physical Science in the Middle Ages, 1971].

Herrera, Samuel y Leonel Toledo, 2018, "Crítica y reforma del conocimiento de las sustancias según la filosofía natural de Pierre Gassendi", en Benítez y Ramos-Alarcón 2018, pp. 263-276.

Leff, Gordon, 1975, William of Ockham. The Metamorphosis of Scholastic Discourse, Manchester University Press/Rowman and Littlefield, Manchester.

Lennon, Thomas M., 1993, The Battle of the Gods and Giants. The Legacies of Descartes and Gassendi. 1655-1715, Princeton University Press, Princeton, Nueva Jersey.

Lenoble, Robert, 1943, Mersenne ou la naissance du mécanisme, J. Vrin, París.

Mendelsohn, Richard L., 2005, The Philosophy of Gottlob Frege, Cambridge University Press, Cambridge, $<$ https://doi.org/10.1017/CBO9780511497964>.

Revista de Filosofía Diánoia, vol. 65, no. 84 (mayo-octubre de 2020) e-ISSN: 1870-4913 • DOI: https://doi.org/10.22201/iifs.18704913e.2020.84.1613 
Mill, John Stuart, 1917, Sistema de lógica inductiva y deductiva, trad. Eduardo Ovejero y Maury, Daniel Jorro, Madrid [1a. ed.: A System of Logic Ratiocinative and Inductive, 1843].

Mohanty, Jitendra Nath, 1989, "Psychologism", en Mark A. Notturno (comp.), Perspectives on Psychologism, E.J. Brill, Leiden/Nueva York/Copenhague/Colonia, pp. 1-10.

Popkin, Richard H., 1983, La historia del escepticismo desde Erasmo hasta Spinoza, trad. Juan José Utrilla, Fondo de Cultura Económica, México.

Toledo Marín, Leonel, 2013, "Pierre Gassendi y la transformación de la filosofía natural en la Modernidad temprana. Algunas perspectivas historiográficas", Scripta Philosophiæ Naturalis, vol. 4, pp. 59-76.

Velázquez Zaragoza, Soledad Alejandra, 2010, "El estatuto de las verdades inmutables en las Meditaciones cartesianas: ¿un platonismo redivivo?", El Hombre y la Máquina, año 22, no. 35, pp. 182-191.

Velázquez Zaragoza, Soledad Alejandra, 2018, "Marin Mersenne: crítico del sustancialismo", en Benítez y Ramos-Alarcón 2018, pp. 247-261.

Wilson, Margaret Dauler, 1990, Descartes, trad. José Antonio Robles, Instituto de Investigaciones Filosóficas-UNAM, México [1a. ed.: Descartes, Routledge and Keagan Paul, Londres, 1978].

Recibido el 15 de febrero de 2019; revisado el 5 de noviembre de 2019; aprobado el 12 de enero de 2020. 